\title{
Predictors of length of stay for initial hospitalization in infants with bronchopulmonary dysplasia
}

\author{
Christopher B. Morrow ${ }^{1} \cdot$ Sharon A. McGrath-Morrow ${ }^{1} \cdot$ Joseph M. Collaco $^{1}$
}

Received: 16 January 2018 / Revised: 27 April 2018 / Accepted: 1 May 2018 / Published online: 8 June 2018

(c) Nature America, Inc., part of Springer Nature 2018

\begin{abstract}
Objective Longer initial hospitalizations for preterm infants with bronchopulmonary dysplasia (BPD) can delay family bonding and attainment of developmental milestones, increase the risk for hospital acquired complications, and increase healthcare costs. The goal of the study was to identify the characteristics associated with longer lengths of hospitalization in this high-risk population.

Study design A retrospective analysis was performed on 660 children (born $\leq 32$ weeks gestation) discharged from 13 Maryland NICUs recruited into an outpatient BPD registry.

Result The mean age of discharge was $4.3 \pm 2.9$ months (median: 3.7 months). Subjects born with lower birthweights and covered by public insurance had longer lengths of hospitalization. Clinical characteristics at discharge associated with longer initial hospitalizations included gastrostomy tube, mechanical ventilation, tracheostomy, pulmonary hypertension, and supplemental oxygen.

Conclusion Identifying the risk factors associated with longer lengths of stay could prompt the implementation of personalized in-hospital interventions to improve outcomes and minimize length of stay in infants with BPD.
\end{abstract}

\section{Introduction}

In the United States, nearly $10 \%$ of all live births are preterm ( $<37$ weeks) with over 55,000 infants born in 2015 weighing $<1500 \mathrm{~g}$ [1]. These premature and very low birth weight (VLBW) infants are at increased risk for developing bronchopulmonary dysplasia (BPD) and its associated comorbidities. While rates of BPD are variable, estimates indicate that the incidence of BPD has remained relatively constant over the past several decades (43\% of infants born 22-28 weeks gestation) [2]. This corresponds to a burden of $\sim 15,000$ new BPD diagnoses each year. While severity of BPD in preterm plays a role in length of stay in preterm infants, recognition of clinical characteristics and risk

Electronic supplementary material The online version of this article (https://doi.org/10.1038/s41372-018-0142-7) contains supplementary material, which is available to authorized users.

Joseph M. Collaco

mcollac1@jhmi.edu

1 Eudowood Division of Pediatric Respiratory Sciences, Johns Hopkins School of Medicine, Baltimore, MD, USA factors associated with longer initial hospitalizations in the subgroup of preterm infants with BPD is a significant first step in initiating personalized strategies to optimize the NICU experience for these critically ill infants, thus favoring long-term outcomes and to initiate attempts to reduce length of stay in these high-risk infants.

Infants with BPD often spend in excess of four months in the NICU with some of the sickest patients spending over a year prior to discharge to home for the first time [3]. Prolonged length of NICU stays correlate with increased exposure to nosocomial infections, developmental delays as well as impaired parent-infant relationships [4]. Strategies reported to improve long-term developmental outcomes could be implemented early on in infants with BPD recognized to be at increased risk for a longer length of NICU stay. Some of these interventions may include increasing the amount of adult talk with preterm infants in the NICU [5], the use of single family rooms [6], and increasing utilization of breast milk [7].

Limited data are published on NICU costs, but the mean cost of care for a ventilated extremely low birth weight infant in the NICU is estimated at over $\$ 200,000$ [8]. Reducing the length of stay for infants requiring prolonged intensive care is an important measure in minimizing 
morbidities, promoting parental bonding, and controlling overall medical costs [9].

Early discharge with neonatal home care can be effective, safe, and cost saving for medically stable infants [10, 11]. Complicating the efforts for early discharge of infants with BPD, however, are the numerous medical complications commonly found in this population that are associated with longer hospitalizations and greater risks for re-admission [2, 12, 13]. Despite these challenges, it is important to identify clinical characteristics associated with prolonged length of NICU stay in infants with BPD in order to develop strategies to safely expedite their discharge from the NICU.

Prior studies have identified some clinical characteristics that may complicate and prolong the NICU course for infants with BPD, including respiratory-related characteristics such as the presence of pulmonary hypertension [1416], use of home oxygen [3], and types of inpatient respiratory support $[12,17]$. Non-respiratory characteristics may also include gastrostomy tube placement [18] and feeding difficulties [4]. In light of this work, our study attempts to provide a more comprehensive analysis of the specific patient characteristics most associated with prolonged NICU length of stay in infants with BPD with the goal of identifying targets to shorten NICU hospitalization durations. Targeted care (e.g., for discharging patient on home ventilators) can certainly reduce lengths of stay dramatically [19]. Although our study is a retrospective study focusing on children recruited from an outpatient BPD clinic, these children were discharged from 13 different NICUs across the state of Maryland. Variability in care has been shown across NICUs in the United States [20, 21]. Nevertheless, in this study we were able to demonstrate risk factors that were consistently associated with an increased length of stay in a variety of NICU settings.

We hypothesized that demographic and clinical characteristics were associated with increased length of stay among preterm infants with BPD. Specifically, we hypothesized that children with BPD requiring interventions for swallowing dysfunction (e.g., gastrostomy tube placement or Nissen fundoplication), advanced airway management, as well as those developing pulmonary hypertension would have prolonged lengths of stay, in part due to their greater respiratory severity and difficulties with home care management. Secondary hypotheses of this study included examining specific medications used while in the NICU for BPD and pulmonary hypertension and the age at which infants with BPD underwent tracheostomy and gastrostomy tube placement in association with length of NICU stay. It should be acknowledged that our study focused on infants with BPD, thus we did not study interventions that reduce the incidence of BPD [22], which could influence length of stay in our population if BPD was averted. To this end, we reviewed medical charts from patients recruited from the
Johns Hopkins Outpatient BPD clinic who were previously hospitalized in 13 different NICUs across the state of Maryland.

\section{Methods}

\section{Study population}

Subjects $(n=660)$ were recruited from the outpatient Johns Hopkins Bronchopulmonary Dysplasia Clinic (Baltimore, MD) between January 2008 and April 2017. Patients seen in clinic were referred from NICUs across the state of Maryland. Inclusion criteria were being born preterm ( $\leq 32$ weeks gestation) as well as being diagnosed with BPD by a pediatric pulmonologist or neonatologist per NICHD criteria [23]. This study was approved by the Johns Hopkins University Institutional Review Board (Protocol \#: NA_00051884), and oral informed consent was obtained from parents/guardians. Use of oral consent was approved by the IRB given the minimal potential risks incurred by subjects.

\section{Demographics/clinical data}

Subjects' insurance coverage type was established using billing records. Median household income was derived from 2010 US census tract data using residential zip codes (US median household income: $\$ 50,502$; State of Maryland median household income: $\$ 70,004)$. Birth weight percentiles reflect birth weights corrected for gestational age [24]. Race/ethnicity were self-reported; for the purposes of analysis, any subjects that were reported to have any non-white ancestry were coded as non-white. The presence of gastrostomy tubes, tracheostomies, Nissen fundoplication, ventricular shunt, PDA requiring ligation, home oxygen, ventilator use, and specific medication use as well as dates of procedures and discharge age were obtained through chart review and denote status at the time of discharge. PDA ligation (or device closure) was pursued at the clinical discretion of the attending neonatologist. Subjects were categorized as having pulmonary hypertension $(\mathrm{PH})$ based on clinically obtained echocardiograms with pulmonary hypertension present on or after 2 months of age [14, 15]. All echocardiograms were reviewed by a board-certified pediatric cardiologist. All medications (diuretics and medications for pulmonary hypertension) prescribed at discharge were prescribed at the clinical discretion of the discharging neonatologist.

\section{Statistical methods}

First, univariate Cox regressions were used to identify potential confounders (demographic characteristics) 
associated with length of initial hospital stay. Second, univariate Cox regressions using clinical variables (independent variable) adjusted for demographic characteristics were used to identify specific clinical variables associated with age at initial discharge (independent variable). Third, significant clinical variables were used to build a multivariate Cox regression models to predict age at initial discharge (again adjusted for appropriate demographic characteristics) by backwards elimination of non-significant clinical variables. STATA IC 11 (StataCorp LP, College Station, TX) was used for analyses. $p$ values $<0.05$ were considered statistically significant.

\section{Results}

\section{Demographics}

A total of 660 subjects were recruited for this study from the Johns Hopkins Bronchopulmonary Dysplasia clinic. Subjects were more likely to be males $(59.6 \%)$ and the mean ( \pm SD) gestational age was $26.1 \pm 2.2$ weeks (range: 22.7-32.0 weeks; median: 26) (Table 1). The mean age at initial discharge from the NICU was $4.3 \pm 2.9$ months (range: 0.5-26.5 months; median age: 3.7). Subjects born at an earlier gestational age $(\mathrm{HR}=1.15$ per additional week; $p<0.001)$ and with lower birth weights $(\mathrm{HR}=2.74$ per additional kilogram; $p<0.001)$ were more likely to have an increased length of stay (Supplemental Table 1). Subjects with reported non-white race/ethnicity $(\mathrm{HR}=0.80$; $p=0.006)$ and subjects covered by public insurance $(\mathrm{HR}=0.74 ; p<0.001)$ were also more likely to have a longer length of stay. Other demographic characteristics including sex, birth weight percentile, and estimated household income were not found to have a statistically significant association with length of stay (Supplemental Table 1).

\section{Clinical characteristics}

All clinical characteristics assessed in Fig. 1 were found to be associated with a statistically significant increase in length of stay (All $t$ tests: $p<0.001$ ) with the exception of critical congenital heart defects $(p=0.76)$ (see also Supplemental Table 2). All of these clinical characteristics remained associated with prolonged length of stay in Cox regression analysis controlling for the demographic characteristics that were associated with length of stay (gestational age, birth weight, race/ethnicity, and public insurance) (Supplemental Table 3).

After stepwise multivariate Cox regression analysis, however, only home mechanical ventilation, gastrostomy tube placement, pulmonary hypertension, supplemental
Table 1 Demographics

\begin{tabular}{|c|c|}
\hline Mean $( \pm$ SD $)$ [range] & $\begin{array}{l}\text { Study population } \\
(n=660)\end{array}$ \\
\hline \multicolumn{2}{|l|}{ Demographic characteristics } \\
\hline Sex (\% male) & 59.6 \\
\hline Gestational age (weeks) & $\begin{array}{l}26.6 \pm 2.2 \\
{[22.7-32]}\end{array}$ \\
\hline Birth weight $(\mathrm{g})$ & $\begin{array}{l}903 \pm 324 \\
{[380-2188]} \\
(n=649)\end{array}$ \\
\hline Birth weight percentile (\%) & $\begin{array}{l}41 \pm 23.6 \\
{[1-95]} \\
(n=649)\end{array}$ \\
\hline Race/ethnicity (\% non-white) & 66.4 \\
\hline Public insurance ( $\%$ yes) & 58.2 \\
\hline Estimated household income (\$’000) & $\begin{array}{l}63.6 \pm 22.4 \\
{[15.6-156.6]}\end{array}$ \\
\hline \multicolumn{2}{|l|}{ Clinical characteristics } \\
\hline Age at initial discharge (months) & $\begin{array}{l}4.3 \pm 2.9 \\
{[0.5-26.5]}\end{array}$ \\
\hline Supplemental oxygen (\% yes) & 37.7 \\
\hline Gastrostomy tube (\% yes) & 20.6 \\
\hline Nissen fundoplication (\% yes) & 14.2 \\
\hline Diuretic use (\% yes) & $\begin{array}{l}58.9 \\
(n=657)\end{array}$ \\
\hline Patent ductus arteriosus ligation (\% yes) & $\begin{array}{l}19.8 \\
(n=657)\end{array}$ \\
\hline Critical congenital heart defect (\% yes) & 0.3 \\
\hline Tracheostomy (\% yes) & 3.6 \\
\hline Mechanical ventilation (\% yes) & 3.0 \\
\hline Ventricular shunt (\% yes) & 8.8 \\
\hline Pulmonary hypertension (\% yes) & 16.2 \\
\hline Pulmonary hypertension meds ( $\%$ yes) & 3.9 \\
\hline Inhaled corticosteroid use (\% yes) & 80.6 \\
\hline
\end{tabular}

oxygen use, and inhaled corticosteroid use (after initial hospital discharge) remained associated with prolonged length of stay (Table 2 and Fig. 2). The need to discharge with home mechanical ventilation was associated with an increase in length of stay of over 9 months ( $\mathrm{HR}=0.28$; $p<$ 0.001) (Table 2). Gastrostomy tube placement was associated with an increase of over 4 months $(\mathrm{HR}=0.28 ; p<$ 0.001). The presence of pulmonary hypertension was associated with an increase in length of stay of almost 3 months $(\mathrm{HR}=0.74 ; p=0.01)$ while the need to discharge with home supplemental oxygen $(\mathrm{HR}=0.83 ; p=0.04)$ and inhaled corticosteroid use (HR $=0.81 ; p=0.04)$ were both associated with an increase of less than 2 months. Of note, the adjusted demographic characteristics that still remained significant in the final model were birth weight $(p<0.001)$ and public insurance $(p=0.001)$, while race/ethnicity $(p=$ $0.39)$ and gestation $(p=0.052)$ were not. 
Fig. 1 Age at initial discharge by clinical characteristics. $p$ value for all clinical characteristics $<0.001$ except critical congenital heart defect where $p=0.76$

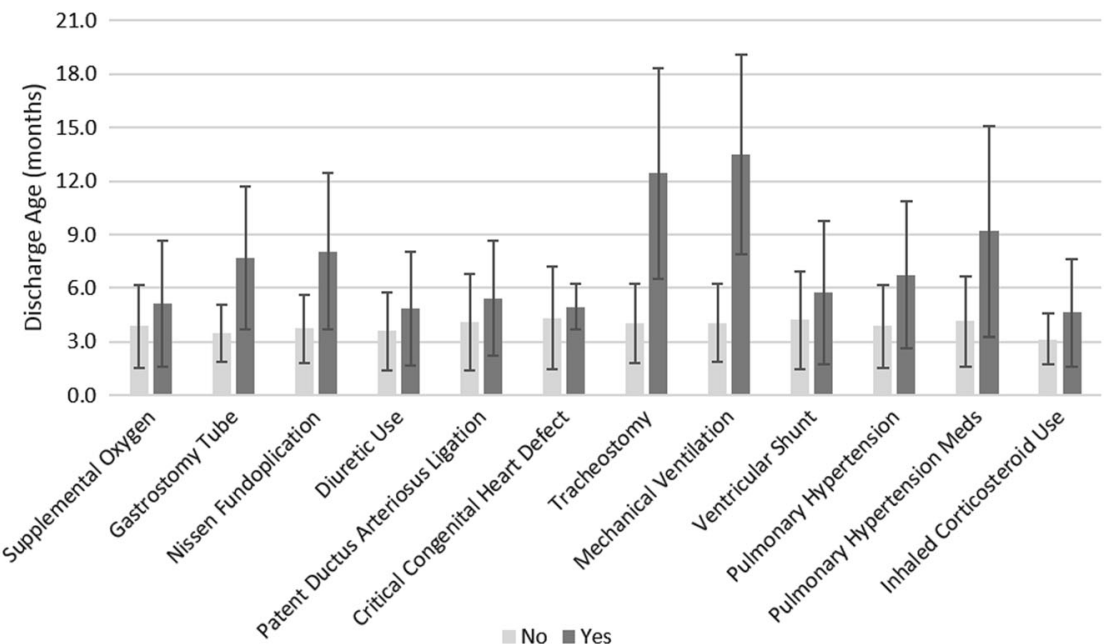

Table 2 Multivariate model for predictors of length of stay

\begin{tabular}{lll}
\hline & $\begin{array}{l}\text { Adjusted Cox regression hazard } \\
\text { ratio }^{\mathrm{a}}[95 \% \mathrm{CI}](n=649)\end{array}$ & $p$ value \\
\hline $\begin{array}{lll}\text { Clinical characteristics } \\
\text { Supplemental oxygen }\end{array}$ & 0.83 & 0.036 \\
Gastrostomy tube & {$[0.71-0.99]$} & $<0.001$ \\
Mechanical ventilation & 0.28 & $<0.001$ \\
& {$[0.22-0.35]$} & \\
Pulmonary & {$[0.16-0.48]$} & 0.012 \\
hypertension & 0.74 & 0.044 \\
Inhaled corticosteroid & {$[0.59-0.94]$} & \\
use & 0.81 & \\
\hline
\end{tabular}

${ }^{\mathrm{a}}$ Final multivariate Cox regression performed to assess for association between clinical characteristics and age of discharge (months) obtained through stepwise regression models of individual predictors associated with age of discharge (Supplemental Table 3). Regression includes adjustments for gestational age, birth weight, race/ethnicity, and public insurance based on univariate models of potential confounders (Supplemental Table 2).

\section{Medication use}

Within the study population, $59.1 \%$ of subjects were prescribed diuretic therapy at discharge (Table 1). Diuretics prescribed for home use within the population included spironolactone, bumetanide, chlorothiazide, and furosemide. The range of use included being prescribed no diuretics to being prescribed a combination of up to three diuretics. Patients who did not receive diuretic prescriptions had a mean length of stay of $3.6 \pm 2.2$ months (median: 3.2 ) (Fig. 3 and Supplemental Table 4). Those patients receiving one diuretic had a mean length of stay of $4.5 \pm 2.6$ months (median: 3.7) while those receiving two diuretics had a mean length of stay of $4.9 \pm 2.8$ months (median: 4.0). Finally, patients receiving three diuretics had a mean length

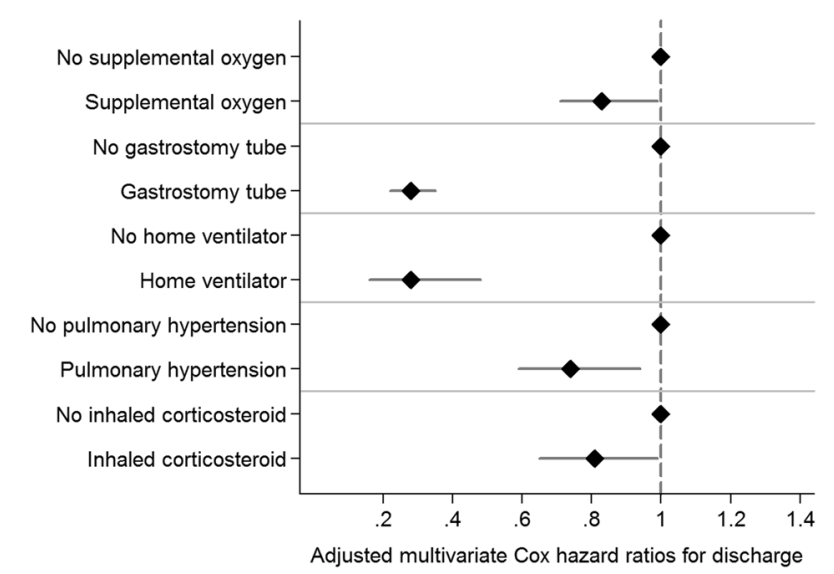

Fig. 2 Significant risk factors for prolonged length of stay from adjusted multivariate model from Table 2 (lower Cox hazard ratios imply more potent risk factors)

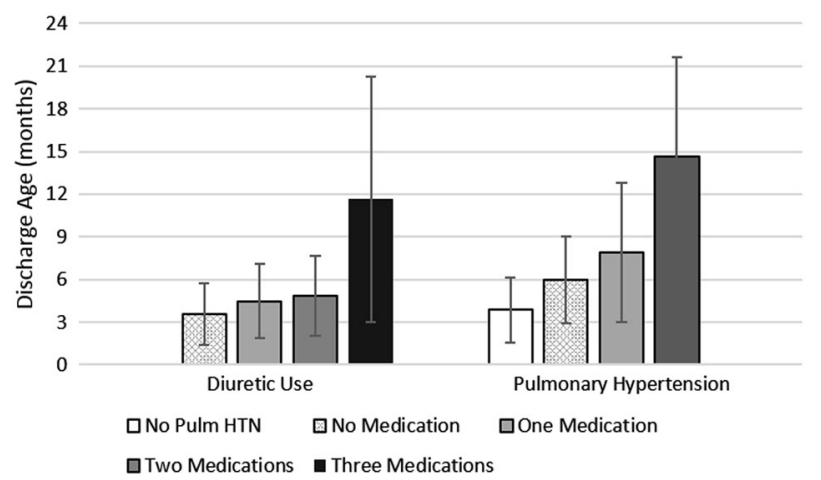

Fig. 3 Diuretics and pulmonary hypertension medications and length of stay

of stay of $11.6 \pm 8.6$ months (median: 10.2). An adjusted Cox regression of the number of diuretic medications prescribed at discharge revealed an association between increased number of diuretics prescribed and prolonged length of stay $(\mathrm{HR}=0.74 ; p<0.001)$. 
In addition, $3.9 \%$ of the study population were prescribed medications to treat pulmonary hypertension at discharge (Table 1). Prescribed medications for management of pulmonary hypertension within the population included sildenafil, treprostinil, and bosentan. Patients with pulmonary hypertension who were prescribed no medications had a mean discharge age of $6.0 \pm 3.1$ months (median: 4.9) (Fig. 3). Patients with pulmonary hypertension who were prescribed one medication had a mean discharge age of $7.9 \pm 4.9$ months (median: 6.5 ) while those on two medications had a mean discharge age of over $14.5 \pm$ 7.0 months (median: 13.6) (Supplemental Table 5). An adjusted Cox regression revealed an association between increased number of medications prescribed and prolonged length of stay $(\mathrm{HR}=0.53 ; p=0.001)$.

\section{Timing of tracheostomy and gastrostomy tube placement}

The mean age at time of tracheostomy placement was 5.6 \pm 2.1 months (median: 5.5) with a mean of $6.9 \pm 5.5$ months (median: 5.3) between tracheostomy placement and initial discharge (Supplemental Table 6). Tracheostomies were placed earlier in the four subjects who did not require home ventilation (mean age: 3.3 months) compared to the 20 subjects who also required home ventilation (mean age: 6.0 months; $p=0.019$ ), but the time between tracheostomy placement and discharge did not differ significantly between the not ventilated (3.3 months) and ventilated subjects (6.0 months; $p=0.21$ ). Also of note, four additional subjects had tracheostomies placed on subsequent admissions.

The mean age of gastrostomy tube placement occurred at $5.4 \pm 1.8$ months (median: 5.3) with a mean of $2.3 \pm$ 3.3 months (median: 0.9) between placement and initial discharge (Supplemental Table 7). Gastrostomies were not placed any earlier in the 42 subjects who did not require home ventilation compared to the 93 subjects who also required Nissen fundoplication $(p=0.84)$, but the time between gastrostomy placement and discharge was shorter for subjects who had gastrostomy tube placement only (mean time: 1.4 months) compared to those who also received a Nissen fundoplication (2.7 months; $p=0.030$ ). Also of note, 39 additional subjects had gastrostomy tubes placed on subsequent admissions.

\section{Discussion}

In this study, we identified demographic and clinical characteristics associated with longer lengths of initial hospitalization in children attending an outpatient BPD clinic. Demographic characteristics associated with longer lengths of stay included lower birthweight as would be expected
[25], but also public insurance. Not surprisingly, the children who required mechanical ventilation at hospital discharge had the longest length of inpatient days. Other clinical characteristics associated with prolonged initial hospitalization included gastrostomy tube placement, the diagnosis of pulmonary hypertension, and supplemental oxygen use. The markedly increased lengths of stay associated with home ventilators and gastrostomy tubes based on the Cox hazard ratios does suggest potential targets for decreasing length of stay, which could involve identifying patients with these needs earlier to proceed with more timely surgical procedures and standardizing post-operative management (e.g., feeding advancement and tracheostomy training) to facilitate earlier discharges. Identifying strategies to reduce the duration of initial hospitalization is important in minimizing risks of infection, reducing health care costs, and mitigating the negative psychological effects on both the infant and family. Furthermore, infants identified early on for being at increased risk for prolonged lengths of stay should be targeted for interventions reported to improve long-term cognitive and motor outcomes in preterm infants [26].

In terms of demographic characteristics, we have previously observed earlier gestational ages and lower birth percentiles in a subset of the current study population, suggesting that patients with lower birth weights are more likely to be categorized as being sicker than preterm infants with higher birth weights [27]. In addition, in the same prior study we observed higher rates of public insurance in nonwhite subjects, which may explain the observed association between public insurance and increased length of stay. Alternatively, many patients in our catchment area with more complex needs, are enrolled in Medicaid (public insurance) as secondary insurance. Of note, in a previous work of a subset of this study population, we found that public insurance was associated with a lower prevalence of re-hospitalization [28], but we cannot comment on a causal link between longer initial length of stay and decreased risk of re-hospitalization. Prospective studies assessing length of stay with regard to future hospitalization would be required to answer this. Social interventions to reduce length of stay may involve better communication between care providers and families (e.g., regular family meetings) or earlier identification of social barriers to discharge.

With regard to clinical characteristics, the diversity of factors we found to be associated with prolonged length of stay highlights the complexity of lung disease that these infants suffer from and the fact that addressing one factor alone may not reduce length of stay across the entire population. More specifically, mechanical ventilation and supplemental oxygen use suggest a component of alveolar disease, with pulmonary hypertension suggesting a component of vascular disease, and inhaled corticosteroid suggesting a 
component of small airways disease or lung inflammation. However, targeted inventions can certainly have a large beneficial effect on specific subgroups. For example, a recent effort in Colorado to standardize initial discharge of pediatric ventilated patients resulted in substantial reduction in mortality, length of stay, and costs $[19,29]$.

We also found that an increased number of medications (diuretics or anti-pulmonary hypertensive agents) prescribed at discharge was also associated with longer length of stay for initial hospitalization. This finding could reflect disease severity, indicating that infants who require these medications had more severe alveolar and vascular disease in the infants. Although Lardon-Fernandez and colleagues reported an association between diuretic use and development of BPD, it was unclear whether diuretic use was directly associated with a longer length of initial hospitalization [30]. Furthermore, variability in delivery of care by regional NICUs could influence development of BPD in a preterm infant as found in California resulting in variability in the initial length of stay in the NICU [20]. In their study, they reported that administration of antenatal corticosteroid varied between regional NICUs in California. Nevertheless, despite coming from a diverse number of regional NICUs, we found an association between use of diuretics or antipulmonary hypertensive agents and longer length of initial hospital stay. A limitation to our study is not knowing the degree of practice variability between the regional NICUs. Of some interest however is whether earlier initiation of these medications during the NICU course could lessen length of stay in these infants.

We also analyzed the number of tracheostomies placed in infants with BPD and although the data was limited, subjects who had tracheostomies placed and were not discharged with home ventilators had their tracheostomies placed almost 3 months earlier than those discharged with home ventilators. Although the difference for time elapsed between tracheostomy placement and discharge was not statistically different between the two groups, we are likely underpowered to detect this difference. In a retrospective study, Hysinger and colleagues reported that neonates with BPD diagnosed with tracheobronchomalacia by bronchoscopy, were more likely to have longer hospitalizations, placement of a tracheostomy and to require mechanical ventilation at discharge [31]. Although clinically we suspect that many children that require home ventilation have some degree of tracheobronchomalacia, this was not determined in our study. In our study population we found no difference in the timing of gastrostomy tube placement between subjects who received a Nissen fundoplication and those who did not, nevertheless subjects who underwent Nissen fundoplication were hospitalized for over 1 month longer, perhaps due to additional recovery time, other comorbidities, or difficulties with feeding compression.
Strengths of our study include the use of a large population of preterm infants diagnosed with BPD while in the NICU with detailed records of medication use and interventions performed during their initial hospitalization. In addition, the subjects in our study were discharged from regional NICUs across the state of Maryland, thus introducing variability in the care of these children during their initial hospitalization. Our results therefore are less likely to be influenced by a single center approach to the treatment of preterm infants in the NICU, potentially increasing the generalizability of our findings. Nevertheless, our subjects were recruited from a single center's outpatient clinic, and patients coming to this center may not be representative of patients with BPD who do not receive treatment from this center. Other limitations include a bias towards a primarily minority population, which may increase the severity of illness in our population and consequently lead to extended NICU stays. Also, we do not have data on ventilatory modes, systemic steroid use, or surfactant use in the NICU or outpatient data on reflux management, which may influence outcomes. In addition, causality cannot be determined from our retrospective analyses in this study. Lastly, patients were recruited over a 9-year period, and it is possible that clinical care changes over that time period may affect results.

In conclusion, our study identifies a number of demographic and clinical risk factors associated with extended initial hospitalization for infants with BPD. Knowledge of these risk factors may be helpful in directing efforts to minimize length of stay in this population, which has important social and economic ramifications; daily NICU costs have been estimated to exceed $\$ 3500$ per infant with prolonged hospitalizations often approaching $\$ 1$ million [32]. In addition, these risk factors may serve as a useful benchmark for forecasting the duration of initial hospitalization in order to improve communication and expectant management for families [33] as the experience of having a newborn with a major medical conditions may negatively impact family dynamics and infant development [34, 35]. Further studies are needed to confirm our findings as well as to establish methods to safely reduce NICU length of stay for infants with BPD. Based on our analyses some potential interventions to reduce length of stay could include establishing specific protocols regarding the use of supplemental oxygen and ventilation in the NICU, advancing gastrostomy feeding, assessing social barriers to discharge earlier in hospital courses, specific protocols for pulmonary hypertension management, standardizing family training regimens, etc. Working to minimize the duration of initial hospitalization for this population may have significant positive implications for the overall outcome of these infants and their families. 
Acknowledgements We thank the families and patients of the Johns Hopkins Bronchopulmonary Dysplasia Clinic, who participated in this study.

Funding This work was supported by Johns Hopkins All Children's Hospital, via an intramural Johns Hopkins Department of Pediatrics grant award to JMC.

\section{Compliance with ethical standards}

Conflict of interest The authors declare that they have no conflict of interest.

\section{References}

1. Martin JA, Hamilton BE, Osterman MJ, Driscoll AK, Mathews TJ. Births: Final Data for 2015. Natl Vital Stat Rep. 2017;66:1. PubMed PMID: 28135188

2. Stoll BJ, Hansen NI, Bell EF, Walsh MC, Carlo WA, Shankaran $\mathrm{S}$, et al. Trends in care practices, morbidity, and mortality of extremely preterm neonates, 1993-2012. JAMA. 2015;314:1039-51. PubMed PMID: 26348753

3. Yeh J, McGrath-Morrow SA, Collaco JM. Oxygen weaning after hospital discharge in children with bronchopulmonary dysplasia. Pediatr Pulmonol. 2016;51:1206-11. PubMed PMID: 27093064

4. Merritt TA, Pillers D, Prows SL. Early NICU discharge of very low birth weight infants: a critical review and analysis. Semin Neonatol. 2003;8:95-115. PubMed PMID: 15001147

5. Caskey M, Stephens B, Tucker R, Vohr B. Adult talk in the NICU with preterm infants and developmental outcomes. Pediatrics. 2014;133:e578-84. PubMed PMID: 24515512

6. Vohr B, McGowan E, McKinley L, Tucker R, Keszler L, Alksninis B. Differential effects of the single-family room neonatal intensive care unit on 18- to 24-month Bayley scores of preterm infants. J Pediatr. 2017;185:42-8e1. PubMed PMID: 28238479

7. Vohr BR, Poindexter BB, Dusick AM, McKinley LT, Wright LL, Langer JC, et al. Beneficial effects of breast milk in the neonatal intensive care unit on the developmental outcome of extremely low birth weight infants at 18 months of age. Pediatrics. 2006;118: e115-23. PubMed PMID: 16818526

8. Meadow W, Cohen-Cutler S, Spelke B, Kim A, Plesac M, Weis $\mathrm{K}$, et al. The prediction and cost of futility in the NICU. Acta Paediatr. 2012;101:397-402. PubMed PMID: 22150563. Pubmed Central PMCID: 4528369

9. American Academy of Pediatrics Committee on Fetus and Newborn. Hospital discharge of the high-risk neonate. Pediatrics. 2008;122:1119-26. PubMed PMID: 18977994

10. Lundberg B, Lindgren C, Palme-Kilander C, Ortenstrand A, Bonamy AK, Sarman I. Hospital-assisted home care after early discharge from a Swedish neonatal intensive care unit was safe and readmissions were rare. Acta Paediatr. 2016;105:895-901. PubMed PMID: 26947937

11. Brooten D, Kumar S, Brown LP, Butts P, Finkler SA, Bakewell-Sachs $\mathrm{S}$, et al. A randomized clinical trial of early hospital discharge and home follow-up of very-low-birth-weight infants. N Eng J Med. 1986;315:934-9. PubMed PMID: 3531852

12. Jackson W, Hornik CP, Messina JA, Guglielmo K, Watwe A, Delancy G, et al. In-hospital outcomes of premature infants with severe bronchopulmonary dysplasia. J Perinatol. 2017;37:853-6. PubMed PMID: 28383537

13. Smith VC, Zupancic JA, McCormick MC, Croen LA, Greene J, Escobar GJ, et al. Rehospitalization in the first year of life among infants with bronchopulmonary dysplasia. J Pediatr. 2004;144: 799-803. PubMed PMID: 15192629
14. Collaco JM, Dadlani GH, Nies MK, Leshko J, Everett AD, McGrath-Morrow SA. Risk factors and clinical outcomes in preterm infants with pulmonary hypertension. PLoS ONE. 2016;11: e0163904. PubMed PMID: 27716811. Pubmed Central PMCID: 5055317

15. Stuart BD, Sekar P, Coulson JD, Choi SE, McGrath-Morrow SA, Collaco JM. Health-care utilization and respiratory morbidities in preterm infants with pulmonary hypertension. J Perinatol. 2013;33:543-7. PubMed PMID: 23328926

16. Nagiub M, Kanaan U, Simon D, Guglani L. Risk factors for development of pulmonary hypertension in infants with bronchopulmonary dysplasia: systematic review and meta-analysis. Paediatr Respir Rev. 2017;23:27-32. PubMed PMID: 28188008

17. Ambalavanan N, Carlo WA, McDonald SA, Yao Q, Das A, Higgins $\mathrm{RD}$, et al. Identification of extremely premature infants at high risk of rehospitalization. Pediatrics. 2011;128:e1216-25. PubMed PMID: 22007016. Pubmed Central PMCID: 3208965

18. McGrath-Morrow SA, Hayashi M, Aherrera AD, Collaco JM. Respiratory outcomes of children with BPD and gastrostomy tubes during the first 2 years of life. Pediatr Pulmonol. 2014;49:537-43. PubMed PMID: 24039081

19. Baker CD, Martin S, Thrasher J, Moore HM, Baker J, Abman SH, et al. A standardized discharge process decreases length of stay for ventilator-dependent children. Pediatrics. 2016;137. pii: e20150637. https://doi.org/10.1542/peds.2015-0637. Epub 2016 Mar 10. PubMed PMID: 26966133.

20. Lapcharoensap W, Gage SC, Kan P, Profit J, Shaw GM, Gould $\mathrm{JB}$, et al. Hospital variation and risk factors for bronchopulmonary dysplasia in a population-based cohort. JAMA Pediatr. 2015;169: e143676. PubMed PMID: 25642906

21. Guaman MC, Gien J, Baker CD, Zhang H, Austin ED, Collaco JM. Point prevalence, clinical characteristics, and treatment variation for infants with severe bronchopulmonary dysplasia. Am J Perinatol. 2015;32:960-7. PubMed PMID: 25738785. Pubmed Central PMCID: 4617756

22. Isayama $\mathrm{T}$, Iwami $\mathrm{H}$, McDonald $\mathrm{S}$, Beyene J. Association of noninvasive ventilation strategies with mortality and bronchopulmonary dysplasia among preterm infants: a systematic review and meta-analysis. JAMA. 2016;316:611-24. PubMed PMID: 27532916

23. Jobe AH, Bancalari E. Bronchopulmonary dysplasia. Am J Respir Crit Care Med. 2001;163:1723-9. PubMed PMID: 11401896

24. Oken E, Kleinman KP, Rich-Edwards J, Gillman MW. A nearly continuous measure of birth weight for gestational age using a United States national reference. BMC Pediatr. 2003;3:6. PubMed PMID: 12848901. Pubmed Central PMCID: 169185

25. Seaton SE, Barker L, Jenkins D, Draper ES, Abrams KR, Manktelow BN. What factors predict length of stay in a neonatal unit: a systematic review. BMJ Open. 2016;6:e010466. PubMed PMID: 27797978. Pubmed Central PMCID: 5073598

26. Spittle A, Orton J, Anderson PJ, Boyd R, Doyle LW. Early developmental intervention programmes provided post hospital discharge to prevent motor and cognitive impairment in preterm infants. Cochrane Database Syst Rev. 2015;24:CD005495. PubMed PMID: 26597166

27. Collaco JM, Aherrera AD, McGrath-Morrow SA. The influence of gender on respiratory outcomes in children with bronchopulmonary dysplasia during the first 3 years of life. Pediatr Pulmonol. 2017;52:217-24. PubMed PMID: 27362897

28. Collaco JM, Choi SJ, Riekert KA, Eakin MN, McGrath-Morrow SA, Okelo SO. Socio-economic factors and outcomes in chronic lung disease of prematurity. Pediatr Pulmonol. 2011;46:709-16. PubMed PMID: 21328574. Pubmed Central PMCID: 3115434

29. Gien J, Kinsella J, Thrasher J, Grenolds A, Abman SH, Baker CD. Retrospective analysis of an interdisciplinary ventilator care program intervention on survival of infants with ventilator-dependent 
bronchopulmonary dysplasia. Am J Perinatol. 2017;34:155-63. PubMed PMID: 27355979. Pubmed Central PMCID: 5199631

30. Lardon-Fernandez M, Uberos J, Molina-Oya M, Narbona-Lopez E. Epidemiological factors involved in the development of bronchopulmonary dysplasia in very low birth-weight preterm infants. Minerva Pediatr. 2017;69:42-9. PubMed PMID: 25715027

31. Hysinger EB, Friedman NL, Padula MA, Shinohara RT, Zhang H, Panitch HB, et al. Tracheobronchomalacia is associated with increased morbidity in bronchopulmonary dysplasia. Ann Am Thorac Soc. 2017 Jun 16. https://doi.org/10.1513/AnnalsATS. 201702-178OC [Epub ahead of print]. PubMed PMID: 28622012.

32. Muraskas J, Parsi K. The cost of saving the tiniest lives: NICUs versus prevention. Virtual Mentor. 2008;10:655-8. PubMed PMID: 23211808
33. Abman SH, Collaco JM, Shepherd EG, Keszler M, CuevasGuaman M, Welty SE, et al. Interdisciplinary care of children with severe bronchopulmonary dysplasia. J Pediatr. 2017;181:12-28e1. PubMed PMID: 27908648

34. Ionio C, Colombo C, Brazzoduro V, Mascheroni E, Confalonieri E, Castoldi F, et al. Mothers and fathers in NICU: the impact of preterm birth on parental distress. Eur J Psychol. 2016;12: 604-21. PubMed PMID: 27872669. Pubmed Central PMCID: 5114875

35. Hoffenkamp HN, Braeken J, Hall RA, Tooten A, Vingerhoets AJ, van Bakel HJ. Parenting in complex conditions: does preterm birth provide a context for the development of less optimal parental behavior? J Pediatr Psychol. 2015;40:559-71. PubMed PMID: 25699688 